\title{
Long working hours and alcohol use: systematic review and meta-analysis of published studies and unpublished individual participant data
}

Marianna Virtanen professor ${ }^{1}$, Markus Jokela associate professor ${ }^{2}$, Solja T Nyberg statistician ${ }^{1}$, Ida E H Madsen researcher ${ }^{3}$, Tea Lallukka specialist researcher ${ }^{14}$, Kirsi Ahola team leader ${ }^{1}$, Lars Alfredsson professor of epidemiology ${ }^{56}$, G David Batty reader in epidemiology ${ }^{789}$, Jakob B Bjorner professor $^{3}$, Marianne Borritz assistant professor ${ }^{10}$, Hermann Burr scientist ${ }^{11}$, Annalisa Casini lecturer $^{12}$, Els Clays postdoctoral researcher ${ }^{13}$, Dirk De Bacquer professor ${ }^{13}$, Nico Dragano professor $^{14}$, Raimund Erbel professor of medicine ${ }^{15}$, Jane E Ferrie senior research fellow ${ }^{716}$, Eleonor I Fransson associate professor ${ }^{517}{ }^{18}$, Mark Hamer principal research associate ${ }^{7}$, Katriina Heikkilä specialist researcher $^{19}$, Karl-Heinz Jöckel professor ${ }^{20}$, France Kittel professor of health psychology and research methodology ${ }^{12}$, Anders Knutsson professor of public health ${ }^{21}$, Markku Koskenvuo professor of epidemiology ${ }^{4}$, Karl-Heinz Ladwig professor of psychosomatic medicine ${ }^{22}$, Thorsten Lunau researcher $^{14}$, Martin L Nielsen consultant ${ }^{23}$, Maria Nordin associate professor of psychology ${ }^{1724}$, Tuula Oksanen assistant chief medical officer ${ }^{1}$, Jan H Pejtersen senior researcher ${ }^{25}$, Jaana Pentti statistician ${ }^{1}$, Reiner Rugulies professor of psychosocial work environment and health ${ }^{326}$, Paula Salo professor of psychology ${ }^{127}$, Jürgen Schupp professor of sociology ${ }^{2829}$, Johannes Siegrist professor $^{14}$, Archana Singh-Manoux research director ${ }^{730}$, Andrew Steptoe British Heart Foundation professor of psychology ${ }^{7}$, Sakari B Suominen professor ${ }^{313233}$, Töres Theorell professor emeritus ${ }^{17}$, Jussi Vahtera professor of public health ${ }^{13134}$, Gert G Wagner professor ${ }^{283536}$, Peter J M Westerholm professor emeritus ${ }^{37}$, Hugo Westerlund professor of epidemiology ${ }^{17}$, Mika Kivimäki professor of social epidemiology ${ }^{147}$

${ }^{1}$ Finnish Institute of Occupational Health, 00250 Helsinki, Finland; ${ }^{2}$ Institute of Behavioral Sciences, University of Helsinki, Helsinki, Finland; ${ }^{3}$ National Research Centre for the Working Environment, Copenhagen, Denmark; ${ }^{4}$ Department of Public Health, Faculty of Medicine, University of Helsinki, Finland; ${ }^{5}$ Institute of Environmental Medicine, Karolinska Institutet, Stockholm, Sweden; ${ }^{6}$ Centre for Occupational and Environmental Medicine, Stockholm County Council, Sweden; ${ }^{7}$ Department of Epidemiology and Public Health, University College London, London, UK; ${ }^{8}$ Alzheimer Scotland Dementia Research Centre, University of Edinburgh, Edinburgh, UK; ${ }^{\circ}$ Centre for Cognitive Ageing and Cognitive Epidemiology, University of Edinburgh, Edinburgh, UK; ${ }^{10}$ Department of Occupational Medicine, Koge Hospital, Koge, Denmark; ${ }^{11}$ Federal Institute for Occupational Safety and Health (BAuA), Berlin, Germany; ${ }^{12}$ School of Public Health, Université Libre de Bruxelles (ULB), Brussels, Belgium; ${ }^{13}$ Department of Public Health, Ghent University, Ghent, Belgium; ${ }^{14}$ Institute for Medical Sociology, Medical Faculty, University of Düsseldorf, Düsseldorf, Germany; ${ }^{15}$ Department of Cardiology, West-German Heart Center Essen, University Duisburg-Essen, Essen, Germany; ${ }^{16}$ School of Social and Community Medicine, University of Bristol, Bristol, UK; ${ }^{17}$ Stress Research Institute, Stockholm University, Stockholm, Sweden; ${ }^{18}$ School of Health Sciences, Jönköping University, Jönköping, Sweden; ${ }^{19}$ School of Medicine, University of Tampere, Tampere, Finland; ${ }^{20}$ Institute for Medical Informatics, Biometry, and Epidemiology, Faculty of Medicine, University Duisburg-Essen, Essen, Germany; ${ }^{21}$ Department of Health Sciences, Mid Sweden University, Sundsvall, Sweden; ${ }^{22} \mathrm{Helmholtz} \mathrm{Zentrum} \mathrm{München} \mathrm{(German} \mathrm{Research} \mathrm{Center} \mathrm{for} \mathrm{Environmental} \mathrm{Health}(\mathrm{GmbH})$ ), 85764 Oberschleißheim, Germany; ${ }^{23}$ Unit of Social Medicine, Frederiksberg University Hospital, Copenhagen, Denmark; ${ }^{24}$ Department of Psychology, Umeå University, Umeå, Sweden; ${ }^{25}$ Danish National Centre for Social Research, Copenhagen, Denmark; ${ }^{26}$ Department of Public Health and Department of Psychology, University of Copenhagen, Copenhagen, Denmark; ${ }^{27}$ Department of Psychology, University of Turku, Turku, Finland; ${ }^{28}$ German Institute for Economic Research, Berlin, Germany; ${ }^{29} \mathrm{Free}$ University of Berlin, Berlin, Germany; ${ }^{30}$ Inserm U1018, Centre for Research in Epidemiology and Population Health, Villejuif, France; ${ }^{31}$ Department of Public Health, University of Turku, Turku, Finland; ${ }^{32}$ Nordic School of Public Health, Gothenburg, Sweden; ${ }^{33}$ Folkhälsan 
Research Center, Helsinki, Finland; ${ }^{34}$ Turku University Hospital, Turku, Finland; ${ }^{35}$ Max Planck Institute for Human Development, Berlin, Germany; ${ }^{36}$ Berlin University of Technology, Berlin, Germany; ${ }^{37}$ Occupational and Environmental Medicine, Uppsala University, Uppsala, Sweden

\begin{abstract}
Objective To quantify the association between long working hours and alcohol use.

Design Systematic review and meta-analysis of published studies and unpublished individual participant data.

Data sources A systematic search of PubMed and Embase databases in April 2014 for published studies, supplemented with manual searches. Unpublished individual participant data were obtained from 27 additional studies.
\end{abstract}

Review methods The search strategy was designed to retrieve cross sectional and prospective studies of the association between long working hours and alcohol use. Summary estimates were obtained with random effects meta-analysis. Sources of heterogeneity were examined with meta-regression.

Results Cross sectional analysis was based on 61 studies representing 333693 participants from 14 countries. Prospective analysis was based on 20 studies representing 100602 participants from nine countries. The pooled maximum adjusted odds ratio for the association between long working hours and alcohol use was 1.11 (95\% confidence interval 1.05 to 1.18) in the cross sectional analysis of published and unpublished data. Odds ratio of new onset risky alcohol use was 1.12 (1.04 to 1.20) in the analysis of prospective published and unpublished data. In the 18 studies with individual participant data it was possible to assess the European Union Working Time Directive, which recommends an upper limit of 48 hours a week. Odds ratios of new onset risky alcohol use for those working 49-54 hours and $\geq 55$ hours a week were 1.13 (1.02 to 1.26; adjusted difference in incidence 0.8 percentage points) and 1.12 (1.01 to 1.25; adjusted difference in incidence 0.7 percentage points), respectively, compared with working standard 35-40 hours (incidence of new onset risky alcohol use $6.2 \%$ ). There was no difference in these associations between men and women or by age or socioeconomic groups, geographical regions, sample type (population based $v$ occupational cohort), prevalence of risky alcohol use in the cohort, or sample attrition rate.

Conclusions Individuals whose working hours exceed standard recommendations are more likely to increase their alcohol use to levels that pose a health risk.

\section{Introduction}

Risky alcohol use is common in high income countries, though there is cultural variation in alcohol use between countries; about one in four people are classified as at risk users, and 9\% meet the diagnostic criteria for an alcohol use disorder. ${ }^{1-4}$ Risky alcohol use, defined for example, as more than 14 drinks/week among women and more than 21 drinks/week among men, ${ }^{5-7}$ refers to the level of alcohol consumption at which there might be an increased risk of adverse health consequences, such as liver diseases, cancer, coronary heart disease, stroke, mental disorders, and injuries, as well as considerable social costs because of family disruption, violence, traffic incidents, healthcare costs, reduced work productivity, and permanent exclusion from the labour market. ${ }^{1-38}$
Although risky alcohol use is common in the workforce, ${ }^{3}$ little attention has been paid to any association with work. A recent large scale meta-analysis of data from individual participants provided no clear support for an association between perceived "job strain" (an index of work stress) and risky alcohol use. Another work related factor-long working hours-has been associated with several adverse health outcomes that are linked to alcohol use, including cardiovascular diseases, ${ }^{10-14}$ depression and anxiety, ${ }^{113-16}$ sleep deprivation, ${ }^{11}{ }^{12} 16$ and occupational injuries. ${ }^{15}{ }^{17}$ Direct evidence on the association between long working hours and alcohol use, however, is based on relatively small studies with insufficient power to detect weak or moderate associations. Three narrative reviews, published in 1999-2006, summarised findings from up to six studies that reported inconclusive results, some studies showing increased alcohol use among people with long working hours, and other studies observing no relation. ${ }^{11}{ }^{13} 18$ To date, there has been no systematic quantification of the link between long working hours and alcohol use.

Meta-analysis is a powerful tool to examine associations between exposures and health outcomes as it is based on a greater range of participants, a larger sample size, and more events than any individual study. A traditional meta-analysis of published studies is a quantitative synthesis of published aggregate data with a limited ability to control for the effects of publication bias (that is, selective reporting of positive findings) and heterogeneity in the methods used (for example, cut-off levels, method of measurement, analytic strategies, etc). ${ }^{19}$ Meta-analysis of individual participant data provides an opportunity to deal with these biases by inclusion of unpublished individual level data to the analysis and by standardisation of definitions of the exposures, outcomes, and statistical methods within these data. ${ }^{20}$

We carried out a meta-analysis of 36 published studies with aggregate data (34 cross sectional and two prospective), identified by a systematic review and supplemented with unpublished individual participant data from 27 studies, of which 18 provided data for prospective analysis. We examined whether long working hours are associated with alcohol use cross sectionally, longitudinally, and in relation to sustained risky alcohol use. We also examined whether any association is apparent across sociodemographic groups, geographical regions, and characteristics of the study cohort. Finally, we compared the findings from published studies and studies with unpublished individual participant data to evaluate publication bias.

\section{Methods}

\section{Search strategy for published studies with aggregate data}

We conducted the meta-analysis according to MOOSE guidelines. ${ }^{21}$ We performed a systematic computerised literature search in PubMed and Embase (to April 2014). Exposure search terms, used without restrictions, were: "(work and hours) or 
(working and hours) or (overtime and work) or overtime". Outcome search terms were: "alcohol or alcohols or ethanol or wine or beer or liquor or spirit or alcoholism or (alcohol and dependence) or (alcohol and abuse) or (substance) or (drinking and behaviour) or (alcohol and drinking) or (alcoholic and beverages) or (alcohol and consumption) or (alcohol and misuse) or (heavy and drinking) or lifestyle or (life and style) or (health and behaviours) or (health and behaviour)". We also scrutinised the reference list of all eligible publications and performed a cited reference search of these using the Institute of Scientific Information Web of Science (to May 2014) to identify all studies citing the included studies.

\section{Study selection criteria}

We included published studies providing aggregate data if they met the following criteria: empirical and peer reviewed study; at least an abstract with estimates and/or full results published in English; individual level exposure and outcome data; examined the association between working hours and alcohol use (reported either by a defined high level of alcohol consumption or as a continuous variable); reported either estimates of relative risk, odds ratios, or hazard ratios with $95 \%$ confidence intervals or data to calculate these. Cross sectional, case-control, prospective studies, and trials were eligible for this meta-analysis.

\section{Data extraction from studies with aggregate data}

We extracted the following information from each retrieved article: name of first author, start of follow-up (year) or publication year if start year not reported, study location (country), population, number of participants, mean follow-up time, mean age or age range, proportion of women, method of assessment and definition of long working hours, proportion of employees with long hours, method of assessment of alcohol use, definition of risky alcohol use (when applicable), proportion of employees with risky use at baseline and proportion of new cases at follow-up, and covariates included in the adjusted models.

\section{Individual participant data}

We also identified 28 datasets with relevant individual participant data. Of these, we excluded the Intervention Project on Absence and Well-being (IPAW) study ${ }^{22}$ from the analysis because there were no cases of risky alcohol use among employees with long working hours. Of the remaining 27 datasets, we obtained 15 from the Individual-Participant-Data Meta-analysis in Working Populations (IPD-Work) Consortium, which we lead, and 12 from open access data collections. The IPD-Work consortium is a network of investigators established at a meeting in London in 2008 to pool cohort studies with data on work life and health. Individual participant data from 15 cohort studies with measurements of working hours and alcohol consumption were available from IPD-Work. Another source of unpublished data was from open access collections. These were retrieved from collections curated by the Inter-University Consortium for Political and Social Research (ICPSR; www. icpsr.umich.edu/icpsrweb/ICPSR/) and the UK Economic and Social Data Service (http://ukdataservice.ac.uk/). These repositories seek research data and pertinent documents from researchers, research agencies, and government entities and process, preserve, and disseminate the data and documents for researchers. We identified 12 additional studies with data on working hours and alcohol use from these two sources (see appendix 1 for a more detailed description). Each constituent study was approved by the relevant local or national ethics committee, and all participants gave informed consent to participate.

In line with previous evidence suggesting $\geq 55$ hours of work a week to be harmful for health, ${ }^{10}$ and the European Union Directive of a recommended limit of 48 hours a week, ${ }^{23}$ we used the following categories of hours worked: $<35,35-40$ (reference), 41-48, 49-54, and $\geq 55$ hours. In the Helsinki Health Study, ${ }^{24}$ weekly working hours were categorised as $<30,30-40$, $41-50$, and $>50$ in the response format. In our analyses, we used the $>50$ working hours group in the Helsinki Health Study to represent the $\geq 55$ hours group and the $30-40$ hours group as the reference group.

In all individual participant data studies, information on alcohol use was based on survey responses. We defined risky alcohol use by standard categorisations. ${ }^{9}$ One drink was considered equivalent to one unit or one glass of alcoholic drink. Participants were classified as follows: non-use or moderate use (up to 14 drinks/week for women and up to 21 drinks/week for men), and risky alcohol use ( $>14$ drinks/week and $>21$ drinks/week, respectively). According to public health guidelines, these limits define risky alcohol use among men and women in many countries. ${ }^{5-7}$ In the German Socioeconomic Panel Survey cohort, ${ }^{25}$ participants were asked how often they drank beer, wine, spirits, and mixed drinks $(0=$ never, $1=$ seldom, $2=$ once in a while, $3=$ regularly); and risky alcohol use was defined as score of 7 or more on the summed score of these four questions. In the US National Longitudinal Survey of Youth 1979 cohort, ${ }^{26}$ risky alcohol use was defined as "binge drinking"- that is, having consumed six or more alcohol units in one evening at least twice during the past month. In the prospective cohort analyses of new onset risky alcohol use, we excluded cases of risky alcohol use at baseline.

\section{Statistical analysis}

We used a two stage meta-analysis ${ }^{20}$ with study specific estimates obtained from published studies with aggregate data and studies with unpublished individual participant data at the first stage. The second stage was an analysis that pooled all the study specific estimates.

\section{First stage analysis in studies with aggregate data}

We converted means, correlation coefficients, and regression coefficients reported for continuous variables to odds ratios according to published formulas. ${ }^{27}$ The studies with aggregate data had used different covariate adjustments. In two published studies, the exposure measure was a continuous variable estimating one hour increase in working hours with a dichotomous alcohol use outcome. ${ }^{28}{ }^{29}$ In these cases, we raised the estimate to the 18th power to get an estimate comparable with that in the individual participant data ( $\geq 55$ hours $v 35-40$ hours-that is, about an 18 hour difference).

\section{First stage analysis in studies with individual participant data}

We analysed data from the individual participant data studies to generate study level odds ratios and $95 \%$ confidence intervals within each study. These analyses were adjusted for age, sex, race/ethnicity (white/ethnic majority $v$ other when available), and socioeconomic status, which was categorised as high, intermediate, and low. In the analyses of individual participant data, this three level socioeconomic status variable was based 
on register or survey based occupational position or educational qualification.

\section{Second stage analysis}

In both types of data, we used random effects meta-analysis to combine the results from the individual participant data analyses and the (converted) estimates of the aggregate data. We used odds ratios as an indicator of effect size and their $95 \%$ confidence intervals as an indicator of precision. We examined heterogeneity of the estimates by computing an $\mathrm{I}^{2}$ statistic, presented the summary estimates of the random effects analyses, and assessed the possibility of publication bias in the analysis of published studies by using a funnel plot of the estimates against their standard errors and Egger's test for small study effects.

We used cross sectional aggregate and individual participant data for prespecified meta-regression and stratified meta-analyses to examine sex (men only, women only, both), region (Europe, North America, Australia/New Zealand, Asia), number of adjustment variables (none, sociodemographics, multivariable), and population (random sample of the population, occupational cohort with several occupations, occupational cohort with a single occupation (except physicians), physicians, patients) as sources of heterogeneity between studies. In the prospective analysis the corresponding variables were sex, age $(<50 v \geq 50)$, socioeconomic status, region (North America, United Kingdom, other Europe, Australia), sample type (population based/community sample $v$ occupational cohort), the baseline level of alcohol use in the cohort $(<9 \% v$ $\geq 9 \%$ ), and participation rate in the prospective cohort ( $<75 \% v$ $\geq 75 \%$ ). We used SAS 9.4 (Cary, NC) and Stata 13.1 (StataCorp, College Station, TX) to analyse study specific data and Stata 13.1 for meta-analyses.

\section{Results}

\section{Aggregate data from published studies}

The literature search identified 3409 citations from PubMed and 2314 from Embase, of which 651 were selected for further review (fig $1 \Downarrow$ ). Of these, 26 fulfilled the eligibility criteria. We identified 10 additional eligible studies from a manual search of the references of the retrieved relevant publications (including reviews and books) and the cited reference search of the articles that were selected for meta-analysis. In total, there were 36 eligible published studies with aggregate data, of which 34 were cross sectional and two were cohort studies.

The total number of participants included in the meta-analysis of published studies with aggregate data was 139112 in the 34 cross sectional analyses and 6873 in the two prospective analyses (see table $\mathrm{A}$ in appendix 2). There were 80345 men and 61983 women; in one study $(n=3657)$ sex distribution was not reported. The study entry year/publication year ranged from 1970 to 2013 . Only two published studies were prospective. ${ }^{28} 30$ Of all published studies, 13 were from Japan, ${ }^{31-43}$ seven from the United States, ${ }^{44-50}$ four from Canada, ${ }^{2829} 5152$ three from Australia ${ }^{53-55}$ two from the UK, ${ }^{56}{ }^{57}$ and one each from New Zealand, ${ }^{58}$ Denmark,,${ }^{59}$ Taiwan, ${ }^{60}$ France, ${ }^{61}$ Spain,,${ }^{62}$ and Sweden. ${ }^{30}$ One study included participants from both Australia and New Zealand.$^{63}$ Altogether 11 studies were general population based $^{28-30} 4043515255$ 58-60; physicians (six studies), ${ }^{47-49} 545661$ industrial workers (four), ${ }^{31} 324145$ office workers (three), ${ }^{34} 3742$ public sector employees (two), ${ }^{38} 57$ nurses (two), ${ }^{46} 63$ transport employees (two), ${ }^{44} 53$ patients (two), ${ }^{35} 36$ information technology engineers (one), ${ }^{39}$ police officers (one), ${ }^{50}$ managers (one),${ }^{33}$ and university graduates (one). ${ }^{62}$ In 15 studies ${ }^{32-37} 39-424550555962$ the association between long working hours and alcohol use was not the main topic of the study - that is, either long working hours or alcohol use were covariates, and unadjusted estimates were usually displayed in a descriptive table.

There was large variation in the assessment of working hours in published studies with aggregate data: 20 studies used a threshold of 45 hours a week or higher ${ }^{33-37}$ 39-41 43 46-49 54 55 58-60 6263 (the highest threshold being $>80$ hours/week ${ }^{47}$ ) while three studies used $>40$ hours $^{3845} 52$ and one study used "frequent overtime" ${ }^{30}$ (see table A in appendix 2). Of these, 10 studies $^{36} 414648545559606263$ used standard hours (such as 35-40 hours/week) as a reference group-most often all hours below the exposure group were included in the reference group. In the 12 remaining studies, working hours were treated as a continuous variable. ${ }^{28} 2931324244505153565761$

With the exception of two studies, ${ }^{28}{ }^{29}$ the studies that treated working hours as a continuous variable also treated alcohol use measure as a continuous variable and reported a correlation or linear regression coefficient between the exposure and outcome (see table A in appendix 2). Two studies calculated the difference in mean alcohol use between groups of working long and shorter hours. ${ }^{39}{ }^{62}$ Probably in part because of large variation in the definition, the prevalence of working long hours also varied substantially, ranging from $4.1 \%$ to $69.8 \%$. Alcohol use was based on self reported frequency from questionnaires or amount of alcohol use, except in one study that used the Composite International Diagnostic Interview (CIDI) to determine DSM-IV diagnoses of alcohol use disorders. ${ }^{58}$ There was also large variation in the definition of risky alcohol use; and its prevalence between studies ranged from $3.4 \%$ to $64.0 \%$.

\section{Individual participant data}

The 27 studies with individual participant data (fig $1 \Downarrow$ and table $B$ in appendix 2) drew on populations from the US (eight studies), ${ }^{26}{ }^{64-69}$ Germany (five), ${ }^{25} 7071$ Denmark (four), ${ }^{72-75}$ the UK (three) ${ }^{76-78}$ Finland (three), ${ }^{24}{ }^{79}{ }^{80}$ Sweden (two ${ }^{81} 82$ Australia (one), ${ }^{83}$ and Belgium (one). ${ }^{84}$ Eighteen studies were population based or community studies, ${ }^{25} 2664-6870-7476777983$ seven were occupational cohorts, ${ }^{24} 757880-8284$ and two were samples of college graduates and their siblings. ${ }^{69}$ Of the studies, 26 provided hourly data on daily or weekly working hours, and in one study the number of hours was pre-categorised. ${ }^{24}$

The cross sectional data from the 27 individual participant data studies came from 194581 participants (89 799 men, 104782 women). The proportion of employees working long hours ( $\geq 55 /$ week) at baseline ranged from $0.8 \%$ to $20.2 \%$ across the studies (overall 7.5\%). The prevalence of risky alcohol use at baseline ( $\mathrm{n}=22857$ cases) varied from $2.3 \%$ to $38.8 \%$, and the overall prevalence was $11.7 \%$. Eighteen prospective cohorts provided data from a second wave, which allowed us to calculate new onset risky alcohol use. The prospective data included 93 729 participants (36 342 men, 57387 women), the follow-up time ranged from 3.4 to 21.9 years (mean 6.0 person years), and the proportion of participants with new onset risky alcohol use $(n=5878$ new cases) ranged from $1.2 \%$ to $17.4 \%$; overall new onset was $6.3 \%$.

\section{Cross sectional association between working hours and alcohol use}

The overall pooled odds ratio of the association between long working hours and alcohol use in the meta-analysis of 61 cross sectional studies was 1.11 (95\% confidence interval 1.05 to 1.18). Similar associations were found in the 27 individual participant data studies (1.10, 1.04 to 1.18 ; fig $2 \Downarrow)$ and published 
studies with aggregate data $(1.12,1.02$ to 1.22 ; fig $3 \Downarrow)$. The $\mathrm{I}^{2}$ statistics suggested significant heterogeneity among published studies with aggregate data $\left(\mathrm{I}^{2}=81 \%, \mathrm{P}<0.001\right)$ but not individual participant data $\left(\mathrm{I}^{2}=18 \%, \mathrm{P}=0.21\right)$. The total pooled $\mathrm{I}^{2}$ was $72 \%$, with $\mathrm{P}<0.001$. In the individual participant data, the overall prevalence of risky alcohol use was $11.8 \%$.

We examined the potential sources for heterogeneity in the aggregate data: sex (men only, women only, both), region (Europe, North America, Australia/New Zealand, Asia), covariate adjustments (none, sociodemographics, multivariate), and population (random sample of the population, occupational cohort with several occupations, occupational cohort with a single occupation (excluding physicians), physicians, patients). Meta-regression models provided no evidence that any of these factors explained the heterogeneity (data not shown; all $\mathrm{P}>0.11$ ).

To examine whether a stricter definition of the exposure and outcome would provide different results in the cross sectional studies with aggregate data, we carried out a meta-analysis in a refined subgroup of studies that fulfilled the following criteria: the exposure and outcome were categorical; the cut point defining long hours was high enough (that is, it did not include employees with working hours close to standard hours, such as 41 hours); the reference group did not include employees with long working hours (such as 50 hours); the outcome was based on a specific definition of risky alcohol use. Six studies were eligible for this analysis. ${ }^{3655558-60}$ The odds ratio for risky alcohol use was 1.14 (95\% confidence interval 0.89 to 1.47 ) and the $\mathrm{I}^{2}$ was $68.6 \%(\mathrm{P}=0.007$; data not shown), again suggesting a similar estimate but with considerably high heterogeneity among published studies.

The funnel plot for published cross sectional studies appears symmetrical (fig $4 \Downarrow$ ) and is not dependent on whether long working hours and alcohol consumption was the main research question in the study or not. No evidence of an association between study size and the estimates was found in Egger's test: 0.12 ( $95 \%$ confidence interval -0.38 to 0.63 ), $\mathrm{P}=0.62$ for the total data; 0.10 ( -0.71 to 0.90$), \mathrm{P}=0.81$ for studies with long hours and alcohol use as the main research question; $0.22(-0.58$ to 1.02$), \mathrm{P}=0.57$ for studies with another main research question.

\section{Prospective association between long working hours and new onset risky alcohol use}

In the meta-analysis of the 18 prospective individual participant data studies and two studies with published aggregate data, participants who used alcohol above the recommended limits at baseline were excluded. The adjusted pooled odds ratio for new onset risky alcohol use was 1.12 (95\% confidence interval 1.04 to 1.20$)$ for those working long hours $(\geq 55$ in the individual participant data studies), compared with those working standard hours (35-40) (fig $5 \Downarrow$ ). The associations were similar in the individual participant data $(1.12,1.01$ to 1.25$)$ and two studies with published aggregate data $(1.10,0.66$ to 1.84$)$. The $\mathrm{I}^{2}$ statistic for heterogeneity was $0 \%(\mathrm{P}=0.96)$ overall; $0 \%(\mathrm{P}=0.99)$ in the individual participant data studies and $56 \%(\mathrm{P}=0.10)$ in the aggregate data.

We further examined whether the prospective associations were similar in men and women, in older $(\geq 50)$ and younger $(<50)$ employees, among socioeconomic groups, in different geographical areas, in different study samples, and different levels of risky drinking $(<9.0 \% v \geq 9.0 \%$ ) in the cohort (fig $6 \Downarrow$ ). The analyses of sex, age, and socioeconomic group were carried out in the individual participant data studies; for geographical region and type of study sample, all prospective studies were included and for the level of drinking, one study with aggregate data $^{28}$ provided data. Although the odds ratio among women seemed greater $(1.36,95 \%$ confidence interval 1.10 to 1.68$)$ than among men $(1.11,0.98$ to 1.25$)$, the difference was not significant $(\mathrm{P}=0.09)$. The associations were not dependent on age or socioeconomic group, region, sample type, or the level of risky drinking in the cohort (all $\mathrm{P}>0.09$ for heterogeneity). To examine whether the association was dependent on sample attrition, we performed the analyses in subgroups with follow-up participation rate of $<75 \% v \geq 75 \%$. The corresponding odds ratio in the former group was 1.18 (1.02 to 1.36) and 1.10 (1.01 to 1.20 ) in the latter, with $\mathrm{P}=0.44$ for heterogeneity (data not shown).

In the individual participant data studies, we examined the association between each working hours category $(<35,41-48$, $49-54$, and $\geq 55$ ) in comparison with 35-40 hours a week associated with risky alcohol use. In the prospective analysis that excluded those who were risky users at baseline (fig $7 \Downarrow$ ), the overall incidence of risky alcohol use was $6.3 \%$ and the incidence among those working 35-40 hours was $6.2 \%$. A part time job ( $<35$ hours) and working 41-48 hours were not associated with new onset risky alcohol use whereas working 49-54 hours was associated with an odds ratio of 1.13 (95\% confidence interval 1.02 to 1.26 ; adjusted difference in incidence 0.8 percentage points) and working 55 hours or more was associated with an odds ratio of 1.12 (1.01 to 1.25 ; adjusted difference in incidence 0.7 percentage points).

In the corresponding cross sectional analysis the adjusted odds ratio of risky alcohol use was 0.94 (95\% confidence interval 0.88 to 1.02 ) for $<35$ hours, 1.03 (0.97 to 1.09 ) for $41-48$ hours, 1.13 (1.05 to 1.22 ) for 49-54 hours, and 1.10 (1.04 to 1.18) for $\geq 55$ hours when compared with standard $35-40$ weekly working hours (data not shown). The adjusted difference in prevalence was 1.5 percentage points among those with 49-54 weekly working hours and 1.1 percentage points among those with 55 hours or more, when compared with the prevalence among employees working 35-40 hours (11.3\%).

Finally, we used the individual participant data studies to examine whether long working hours were associated with sustained risky alcohol use among those who were risky users at baseline (data not shown). The odds ratio for sustained risky alcohol use among risky users who worked $\geq 55$ hours at baseline was 1.16 (95\% confidence interval 0.83 to 1.61$)$ compared with those working standard 35-40 hours a week, suggesting a similar though non-significant association to that found for new onset risky use among non-risky users at baseline.

\section{Discussion}

This systematic review and meta-analysis of 63 studies provides comprehensive evidence of an association between long working hours and alcohol use. Long working hours were associated with 1.11-fold likelihood of higher levels of alcohol use in the cross sectional analysis of 333693 participants from 14 countries. A similar association (odds ratio 1.12) for new onset risky alcohol use was observed in a prospective analysis of 20 studies including 100602 participants from nine countries. The associations were not dependent on participants' sex, age, socioeconomic status, geographical region, type of study sample, prevalence of risky alcohol use in the cohort, or participation rate at follow-up. Eighteen prospective studies with individual participant data allowed us to perform a more refined comparison between work hour categories. Compared with the standard (35-40) weekly working hours, working 49-54 hours was associated with an odds ratio of 1.13 and working $\geq 55$ 
hours a week was associated with an odds ratio of 1.12 for new onset risky alcohol use.

\section{Strengths and limitations}

Our systematic review and meta-analysis provides the first quantitative summary estimate of the association between long working hours and alcohol use. This has not been provided in previous narrative reviews. ${ }^{11}{ }^{13}{ }^{18} \mathrm{We}$ found only two published studies with a prospective design. Our meta-analysis, however, included 18 prospective cohort studies with unpublished individual participant data, which allowed us to examine the prospective association between long working hours and the onset of risky alcohol use in a large dataset with a harmonised exposure and outcome measurements.

Comparison of published studies with aggregate data and studies with unpublished individual participant data allowed us to account for publication bias, which can bias results from meta-analyses that use only published studies. ${ }^{19} \mathrm{We}$ observed no evidence for publication bias. Firstly, we found similar associations among both types of study. Secondly, statistical assessment of publication bias among published studies, stratified by whether long working hours and alcohol use was the main or secondary research question, and use of a funnel plot and Egger's test of a small study effect suggested no indication of publication bias.

The present meta-analysis has limitations. With the exception of three published studies that used roster or payroll data, ${ }^{39} 5053$ exposure to long working hours was based on self reports and measured only once. Prolonged exposure to long working hours, as identified in repeat data, might carry a greater risk of risky alcohol use than long working hours measured only once. Self reported working hours might involve recall bias arising from the inability of the employees to accurately recall hours worked. Some investigators, however, have shown that self reported work hours is a reliable measure (for example, two week test-retest intraclass correlation coefficient $r=0.91),{ }^{85}$ and a major bias in longitudinal analysis is likely only if the error in estimating the number of hours worked varies according to alcohol use.

Alcohol use was based on self reported frequency or amount of alcohol used, except in one cross sectional study that used the Composite International Diagnostic Interview (CIDI) to assess DSM-IV diagnoses of alcohol use disorders. ${ }^{58}$ Under-reporting of alcohol use has been shown to occur in survey questionnaires ${ }^{87}$ and might be particularly common in heavy drinkers. A major bias would occur if under-reporting was also associated with reporting of working hours. Misclassification of alcohol use could have introduced heterogeneity into the meta-analyses.

Furthermore, this meta-analysis was based on observational studies, which are generalisable only within the study context. Despite cultural variations in drinking habits, even between developed countries, ${ }^{1}$ our findings regarding long working hours and alcohol use were similar across the different geographical regions examined. Our results are also in accordance with global reports of alcohol use, which have shown large differences in alcohol consumption between countries. ${ }^{1}$ We found, for example, that the prevalence of risky alcohol use was lower in the US than in Europe. Although the prevalence of risky alcohol use varied substantially among the cohorts, we found no evidence to suggest that the association between long working hours and alcohol use would be dependent on the prevalence of risky alcohol use in the cohort.
Even though our IPD-Work collaboration includes several major cohort studies in Europe and the two open access databases are large, including cohorts from the US, UK, and Australia, the meta-analysis of individual participant data is based on a convenience sample and does not include all potential data. Thus, availability bias might have affected the findings. ${ }^{19}$ Finally, it is not possible to draw causal inference based on observational studies, which means that our data cannot provide direct evidence for policy recommendations.$^{88}$ Prospective analyses, however, allowed us to get some indication of temporal order of associations, which is consistent with a causal effect, and partially overcomes the problem of reverse causality (risky alcohol use leading to longer working hours), which can bias cross sectional analyses.

\section{Comparison with previous research and sources of heterogeneity}

Previous narrative reviews of long working hours and alcohol use including up to six studies have reported mixed findings. ${ }^{11318}$ Similarly, we observed substantial heterogeneity among published studies with aggregate data $\left(\mathrm{I}^{2}=81 \%, \mathrm{P}<0.001\right)$. Importantly, this heterogeneity was not present in the meta-analysis of individual participant data studies with harmonised exposure and outcome measures $\left(\mathrm{I}^{2}=18 \%, \mathrm{P}=0.21\right.$ in the cross-sectional analysis; $0 \%, \mathrm{P}=0.99$ in the prospective analysis). None of the potential sources of heterogeneity examined in this study explained the heterogeneity found among the cross sectional studies with aggregate data. We explored whether use of a definition of the exposure and outcome close to that used in the individual participant data studies would remove the heterogeneity observed in the six published studies but found no such reduction $\left(\mathrm{I}^{2}=68.6 \%, \mathrm{P}=0.007\right)$. It seems that the sources of heterogeneity must relate to other differences between published studies with aggregate data.

\section{Interpretation of findings}

In this meta-analysis, working very long hours ( $\geq 55$ a week) was associated with a 1.12-fold increase in the odds ratio of new onset risky alcohol use among employees whose alcohol use was within the recommended limits at baseline. A similar (1.13-fold) association was found among those who worked 49-54 hours a week. To protect employee health and safety, the European Union Working Time Directive requires EU countries to guarantee all workers the right to work a maximum of 48 hours a week, on average, including overtime. ${ }^{23}$ This threshold is supported by our analyses. At risk alcohol use has previously been associated with increased risk of liver cirrhosis, cancers, seizure disorders, and stroke. ${ }^{2}$ A recent meta-analysis of 56 epidemiological studies using Mendelian randomisation analysis suggested that reduction of alcohol consumption, even for light to moderate drinkers, might be beneficial for cardiovascular health. ${ }^{89}$

Possible explanations for the association between long working hours and risky alcohol use might involve the work environment as well as individual characteristics. ${ }^{90}$ One view is that alcohol use alleviates stress that is caused by work pressure and working conditions. Working overtime and characteristics such as high demands and lack of control might contribute to stress at work. ${ }^{91}{ }^{92}$ Although our recent individual participant data meta-analysis found little evidence to support a combination of high demands and low job control as a predictor of risky alcohol use, ${ }^{9}$ it remains to be investigated whether a combination of long working hours and low control over work increases the risk. It has also been hypothesised that employees who are not 
well integrated and supervised by the work organisation are at a higher risk of developing alcohol use problems. ${ }^{90}$

Depression and sleep problems might contribute to the link between long working hours and alcohol use. ${ }^{16}$ Other factors, such as personality traits, could confound the association because they might make people work long hours and also be related to a tendency to risky alcohol use. For example, individuals with "type A" behaviour pattern, ${ }^{93}$ which is characterised by aggressiveness and irritability and a chronic struggle to achieve more and more in less and less time, ${ }^{94}$ can end up in highly competitive jobs and work communities characterised by a "work hard play hard" culture with positive attitudes towards heavy alcohol use. ${ }^{95} 96$ Personality traits of impulsivity and novelty seeking have also been found to be associated with risky alcohol use. ${ }^{97}$

Although the legislation in European countries provides employees with the right to restrict maximum working hours to 48 hours a week, many people still work long hours either as their own choice or because of external pressure to do so. ${ }^{98}$ Choosing to work long hours is common among the higher socioeconomic groups, with highly educated managers and professionals expecting dedication to work from themselves and others. This strategy can be highly rewarding in terms of rapid promotions, salary increases, and control over work. On the other hand, involuntary long hours could reflect, for example, financial difficulties and striving for a living wage or coercion. We did not find differences in the association between long working hours and risky alcohol use between socioeconomic groups. It is possible that voluntary and involuntary overtime is more evenly distributed across socioeconomic groups than previously thought.

\section{Conclusions and unanswered questions}

The workplace is an important setting for the prevention of alcohol misuse because more than half of the adult population are employed. ${ }^{4}$ Risky alcohol use is an issue in the workplace because it can have adverse and serious effects on employees, such as absenteeism, ${ }^{80}$ inefficiency, poor performance, impaired decision making, damaged customer relations, and injuries at work. ${ }^{2-48}$ Brief interventions by healthcare personnel that involve assessment of the individual's drinking habits in combination with feedback about health risks might be useful in efforts to reduce problems with alcohol use in the working population. ${ }^{4}$ Our findings suggest that alcohol consumption is more likely to rise to risky levels among employees who work more than 48 hours a week compared with those with standard working hours. In absolute terms, however, the difference between these groups was relatively small because the adjusted incidence in new onset risky alcohol use was only 0.8 and 0.7 percentage points higher among individuals who worked 49-54 and 55 hours or more compared with those who worked standard hours. Further research is needed to assess whether preventive interventions against risky alcohol use could benefit from information on working hours.

Contributors: MV and MK developed the hypothesis and study design and supervised this study. MJ, MV, SN, IM, and TL performed statistical analyses. All authors contributed to study concept and design, analysis and interpretation of data, and drafting or critical revision of the manuscript for important intellectual content, or in addition, data acquisition. MV and KA performed the literature searches and/or screened papers. MK, TT, RR, and ND obtained funding for the IPD-Work Consortium. MJ, SN, and MK had full access to individual participant data in the study and take responsibility for the integrity of the unpublished data and the accuracy of the data analysis. MV is guarantor.

Funding: The IPD-Work Consortium is supported by the EU New OSH ERA Research Program (funded by the Finnish Work Environment Fund and the Academy of Finland, Finland; the Swedish Research Council for Health, Working Life and Welfare, Sweden; the German Social Accident Insurance, Germany; and the Danish Work Environment Research Fund, Denmark); the BUPA Foundation (grant 22094477), and the Dutch Ministry of Social Affairs and Employment, Netherlands. MV is supported by the Academy of Finland (grants 258598, 265174), MK is supported by the Medical Research Council (grant K013351), the Economic and Social Research Council, and the US National Institutes of Health (grants R01HL036310 and R01AG034454), and SN is supported by the Finnish Work Environment Fund. AS is a BHF professor. Funding bodies for each participating cohort study are listed on their websites. The sponsors had no role in design and conduct of the study; collection, management, analysis, and interpretation of the data; and preparation, review, or approval of this manuscript.

Competing interests: All authors have completed the ICMJE uniform disclosure form at www.icmje.org/coi_disclosure.pdf and declare: no support from any organisation for the submitted work other than those mentioned above; no financial relationships with any organisations that might have an interest in the submitted work in the previous three years; no other relationships or activities that could appear to have influenced the submitted work.

Ethical approval: Each constituent study with individual participant data was approved by the relevant local or national ethics committee, and all participants gave informed consent to participate.

Data sharing: No additional data from our meta-analysis are available. Data for ACL, ALAMEDA, BCS, HILDA, MIDUS, NCDS, NHANES-I,

NLSY, NSFH, SOEP, WLSG, and WLSS studies are publicly available to researchers. In addition, most constituent studies of the IPD-Work consortium have an established data sharing policy.

Transparency: MV affirms that this manuscript is an honest, accurate, and transparent account of the study being reported; that no important aspects of the study have been omitted; and that any discrepancies from the study as planned (and, if relevant, registered) have been explained.

World Health Organization. Global status report on alcohol and health 2014. WHO, 2014 Friedmann PD. Clinical practice. Alcohol use in adults. N Engl J Med 2013;368:365-73. Alcohol in the workplace. Institute of Alcohol Studies (IAS), 2014.

Nicholson P, Mayho G, Sharp C. Alcohol, drugs and the workplace. The role of medical professionals. A briefing from the BMA Occupational Medicine Committee. BMA, 2014. International Centre for Alcohol Policies. International drinking guidelines, 2010.

6 United States Department of Agriculture and Department of Health and Human Services. Dietary guidelines for Americans 2010. US Government Printing Office, 2010.

7 National Institute for Health and Clinical Excellence. Alcohol-use disorders: preventing the development of hazardous and harmful drinking. NICE, 2010.

8 Stockwell T, Gruenewald PJ, Toumbourou JW, Loxley W. Preventing risky drug use and related harms: the need for a synthesis of new knowledge. In: Stockwell T, Gruenewald PJ, Toumbourou JW, Loxley W, eds. Preventing harmful substance use The evidence for policy and practice. John Wiley, 2005.

9 Heikkila K, Nyberg ST, Fransson El, Alfredsson L, De Bacquer D, Bjorner JB, et al. Job strain and alcohol intake: a collaborative meta-analysis of individual-participant data from 140,000 men and women. PloS One 2012;7:e40101.

10 Virtanen M, Heikkilä K, Jokela M, Ferrie JE, Batty GD, Vahtera J, et al. Long working hours and coronary heart disease: a systematic review and meta-analysis. Am J Epidemiol 2012;176:586-96.

11 Van der Hulst M. Long workhours and health. Scand J Work Environ Health 2003;29:171-88.

12 Harma M. Are long workhours a health risk? Scand J Work Environ Health 2003;29:167-9.

13 Kawakami N, Haratani T. Epidemiology of job stress and health in Japan: review of current evidence and future direction. Ind Health 1999;37:174-86.

14 Sparks K, Cooper C, Fried Y, Shirom A. The effects of hours of work on health: a meta-analytic review. J Occup Organ Psychol 1997;70:391-408.

15 Spurgeon A, Harrington JM, Cooper CL. Health and safety problems associated with long working hours: a review of the current position. Occup Environ Med 1997;54:367-75.

16 Bannai A, Tamakoshi A. The association between long working hours and health: a systematic review of epidemiological evidence. Scand J Work Environ Health 2014;40:5-18

17 Wagstaff AS, Sigstad Lie JA. Shift and night work and long working hours-a systematic review of safety implications. Scand J Work Environ Health 2011;37:173-85.

18 Caruso CC. Possible broad impacts of long work hours. Ind Health 2006;44:531-6.

19 Abo-Zaid G, Sauerbrei W, Riley RD. Individual participant data meta-analysis of prognostic factor studies: state of the art? BMC Med Res Methodol 2012;12:56. 


\section{What is already known on this topic}

The European Union Working Time Directive threshold for long working hours is 48 hours a week

Long working hours are thought to increase the risk of cardiovascular diseases, sleep deprivation, occupational injuries, and mental health problems

The association between long working hours and risky alcohol use has not been systematically evaluated

\section{What this study adds}

This meta-analysis of 36 published studies, identified by systematic literature searches, and 27 studies with unpublished individual participant data synthesised evidence on the association between long working hours and alcohol use

Long working hours were linked to increased alcohol use in cross sectional and prospective analyses. People working more than 48 hours a week at baseline had 1.13 times higher likelihood of new onset risky alcohol use compared with those working standard hours No heterogeneity was observed between men and women or by age group, socioeconomic status, geographical region, or characteristics of the study cohort

20 Riley RD, Lambert PC, Abo-Zaid G. Meta-analysis of individual participant data: rationale, conduct, and reporting. BMJ 2010;340:c221.

21 Stroup DF, Berlin JA, Morton SC, Olkin I, Williamsson GD, Rennie D, et al. Meta-analysis of observational studies in epidemiology: a proposal for reporting. Meta-analysis Of Observational Studies in Epidemiology (MOOSE) group. JAMA 2000;283:2008-12.

22 Nielsen M, Kristensen T, Smith-Hansen L. The intervention project on absence and well-being (IPAW): design and results from the baseline of a 5-year study. Work Stress 2002;16:191-206.

23 European Commission. Working conditions-working time directive 2014. http://ec.europa. eu/social/main.jsp?catld=706\&langld=en\&intPageld=205.

24 Lahelma E, Aittomaki A, Laaksonen M, Lallukka T, Martikainen P, Piha K, et al. Cohort profile: the Helsinki Health Study. Int J Epidemiol 2013;42:722-30.

25 Schupp J. [The socioeconomic panel (SOEP)]. Bundesgesundheitsblatt Gesundheitsforschung Gesundheitsschutz 2012;55:767-74

26 Statistics BoL. The NLSY79: NLS Handbook. Department of Labor, 2005.

27 Borenstein M, Hedges LV, Higgins JPT, Rothstein HR. Introduction to meta-analysis. John Wiley, 2009.

28 Marchand A, Blanc ME. Occupation, work organization conditions, and alcohol misuse in Canada: an 8-year longitudinal study. Subst Use Misuse 2011;46:1003-14.

29 Marchand A, Parent-Lamarche A, Blanc ME. Work and high-risk alcohol consumption in the Canadian workforce. Int J Environ Res Public Health 2011;8:2692-705.

30 Bildt $\mathrm{C}$, Michelsen $\mathrm{H}$. Gender differences in the effects from working conditions on mental health: a 4-year follow-up. Int Arch Occup Environ Health 2002;75:252-8.

31 Kawakami N, Araki S, Haratani T, Hemmi T. Relations of work stress to alcohol use and drinking problems in male and female employees of a computer factory in Japan. Environ Res 1993;62:314-24.

32 Ezoe S, Morimoto K. Behavioral lifestyle and mental health status of Japanese factory workers. Prev Med 1994;23:98-105

33 Maruyama S, Kohno K, Morimoto K. [A study of preventive medicine in relation to mental health among middle-management employees (Part 2)—effects of long working hours on lifestyles, perceived stress and working-life satisfaction among white-collar middle-management employees]. Nihon Eiseigaku Zasshi 1995;50:849-60.

34 Nakanishi N, Nakamura K, Ichikawa S, Suzuki K, Tatara K. Lifestyle and the developmen of hypertension: a 3-year follow-up study of middle-aged Japanese male office workers. Occup Med (Lond) 1999;49:109-14.

35 Uchiyama S, Kurasawa T, Sekizawa T, Nakatsuka H. Job strain and risk of cardiovascula events in treated hypertensive Japanese workers: hypertension follow-up group study. $J$ Occup Health 2005;47:102-11.

36 Liu Y, Tanaka H. Overtime work, insufficient sleep, and risk of non-fatal acute myocardial infarction in Japanese men. Occup Environ Med 2002;59:447-51.

37 Tarumi K, Hagihara A, Morimoto K. A prospective observation of onsets of health defects associated with working hours. Ind Health 2003;41:101-8.

38 Lallukka T, Lahelma E, Rahkonen O, Roos E, Laaksonen M, Martikainen P, et al. Associations of job strain and working overtime with adverse health behaviors and obesity: evidence from the Whitehall II Study, Helsinki Health Study, and the Japanese Civil Servants Study. Soc Sci Med 2008;66:1681-98.

39 Nishikitani M, Nakao M, Karita K, Nomura K, Yano E. Influence of overtime work, sleep duration, and perceived job characteristics on the physical and mental status of software engineers. Ind Health 2005;43:623-9.

40 Otsuka Y, Sasaki T, Iwasaki K, Mori I. Working hours, coping skills, and psychological health in Japanese daytime workers. Ind Health 2009;47:22-32.

41 Kobayashi T, Suzuki E, Takao S, Doi H. Long working hours and metabolic syndrome among Japanese men: a cross-sectional study. BMC Public Health 2012;12:395.

42 Nakata A, Takahashi M, Irie M. Association of overtime work with cellular immune markers among healthy daytime white-collar employees. Scand $J$ Work Environ Health 2012;38:56-64.

43 Hasegawa T, Murata C, Ninomiya T, Takabayashi T, Noda T, Hayasaka S, et al. Occupational factors and problem drinking among a Japanese working population. Ind Health 2013;51:490-500

44 Seaman FJ. The etiology of problem drinking in the workplace. Drug Alcohol Dep 1981;7:285-93.

45 Proctor SP, White RF, Robins TG, Echeverria D, Rocskay AZ. Effect of overtime work on cognitive function in automotive workers. Scand J Work Environ Health 1996;22:124-32.

46 Trinkoff AM, Storr CL. Work schedule characteristics and substance use in nurses. Am $J$ Ind Med 1998;34:266-71.

47 Baldwin DC, Jr., Daugherty SR, Tsai R, Scotti MJ, Jr. A national survey of residents' self-reported work hours: thinking beyond specialty. Acad Med 2003;78:1154-63.

48 Bazargan M, Makar M, Bazargan-Hejazi S, Ani C, Wolf KE. Preventive, lifestyle, and personal health behaviors among physicians. Acad Psychiatry 2009;33:289-95.

49 de Oliveira GS Jr, Chang R, Fitzgerald PC, Almeida MD, Castro-Alves LS, Ahmad S, et al. The prevalence of burnout and depression and their association with adherence to safety and practice standards: a survey of United States anesthesiology trainees. Anesth Analg 2013;117:182-93.
50 Gu JK, Charles LE, Burchfiel CM, Fekedulegn D, Sarkisian K, Andrew ME, et al. Long work hours and adiposity among police officers in a US northeast city. J Occup Environ Med 2012;54:1374-81.

51 Marchand A, Demers A, Durand P, Simard M. Occupational variations in drinking and psychosocial distress: a multilevel analysis. Work 2003;21:153-63.

52 Shields M. Long working hours and health. Health Rep 1999;11:33-48.

53 Raggatt $P$. Work stress among long-distance coach drivers: a survey and correlational study. J Organ Behav 1991;12:565-79.

54 Nash LM, Daly MG, Kelly PJ, van Ekert EH, Walter G, Walton M, et al. Factors associated with psychiatric morbidity and hazardous alcohol use in Australian doctors. Med J Aust 2010;193:161-6.

$55 \mathrm{Au}$ N, Hauck K, Hollingsworth B. Employment, work hours and weight gain among middle-aged women. Int J Obes (Lond) 2013;37:718-24

56 Baldwin PJ, Dodd M, Wrate RW. Young doctors' health. I. How do working conditions affect attitudes, health and performance? Soc Sci Med 1997;45:35-40

57 Jones F, O'Connor DB, Conner M, McMillan B, Ferguson E. Impact of daily mood, work hours, and iso-strain variables on self-reported health behaviors. J Appl Psychol 2007;92:1731-40.

58 Gibb SJ, Fergusson DM, Horwood LJ. Working hours and alcohol problems in early adulthood. Addiction 2012;107:81-8.

59 Holtermann A, Mortensen OS, Burr H, Sogaard K, Gyntelberg F, Suadicani P. Long work hours and physical fitness: 30 -year risk of ischaemic heart disease and all-cause mortality among middle-aged Caucasian men. Heart 2010;96:1638-44.

60 Cheng WJ, Cheng Y, Huang MC, Chen CJ. Alcohol dependence, consumption of alcoholic energy drinks and associated work characteristics in the Taiwan working population. Alcohol Alcohol 2012:47:372-9.

61 Speicher C, Khodabux N, Lacerre F, Hiar S, Schmitt L, Bui E. Alcohol use in French medical residents. European Psychiatry Conference: 18th European Congress of Psychiatry Munich, Germany. Elsevier Masson SAS, 2010.

62 Pimenta AM, Beunza JJ, Bes-Rastrollo M, Alonso A, Lopez CN, Velasquez Melendez $G$, et al. Work hours and incidence of hypertension among Spanish university graduates: the Seguimiento Universidad de Navarra prospective cohort. J Hypertens 2009;27:34-40.

63 Schluter PJ, Turner C, Benefer C. Long working hours and alcohol risk among Australian and New Zealand nurses and midwives: a cross-sectional study. Int J Nurs Stud 2012;49:701-9.

64 Berkman L, Breslow L. Health and ways of living: the Alameda County Study. Oxford University Press, 1983.

65 Madans JH, Kleinman JC, Cox CS, Barbano HE, Feldman JJ, Cohen B, et al. 10 years after NHANES I: report of initial followup, 1982-84. Public Health Rep 1986;101:465-73.

66 House JS, Lantz PM, Herd P. Continuity and change in the social stratification of aging and health over the life course: evidence from a nationally representative longitudinal study from 1986 to 2001/2002 (Americans' Changing Lives Study). J Gerontol B Psychol Sci Soc Sci 2005:60:15-26.

67 Sweet J, Bumpass L, Call V. The design and content of the National Survey of Families and Household. University of Wisconsin, Center for Demography and Ecology, 1988.

68 Brim O, Baltes P, Bumpass L, Cleary P, Featherman D, Hazzard WR, et al. National survey of midlife development in the United States (MIDUS),1995-1996. ICPSR 2760, 2010. www.icpsr.umich.edu/icpsrweb/ICPSR/series/203/studies/2760.

69 Sewell WH, Houser RM. Education, occupation, and earnings: achievement in the early career. Academic, 1975

70 Holle R, Happich M, Lowel H, Wichmann HE. KORA—a research platform for population-based health research. Gesundheitswesen 2005;67:S19-25.

71 Schmermund A, Mohlenkamp S, Stang A, Grönemeyer D, Seibel R, Hirche H, et al. Assessment of clinically silent atherosclerotic disease and established and novel risk factors for predicting myocardial infarction and cardiac death in healthy middle-aged subjects: rationale and design of the Heinz Nixdorf RECALL Study. Risk Factors, Evaluation of Coronary Calcium and Lifestyle. Am Heart J 2002;144:212-8.

72 Feveile H, Olsen O, Burr H, Bach E. Danish Work Environment Cohort Study 2005: from idea to sampling design. Stat Transit 2007;8:441-58.

73 Pejtersen JH, Kristensen TS, Borg V, Bjorner JB. The second version of the Copenhagen psychosocial questionnaire. Scand J Public Health 2010;38:8-24.

74 Poulsen OM, Persson R, Kristiansen J, Andersen LL, Villadsen E, Orbaek P. Distribution of subjective health complaints, and their association with register based sickness absence in the Danish working population. Scand J Public Health 2013;41:150-7.

75 Borritz M, Rugulies R, Bjorner JB, Villadsen E, Mikkelsen OA, Kristensen TS. Burnout among employees in human service work: design and baseline findings of the PUMA study. Scand J Public Health 2006;34:49-58.

76 Elliott J, Shepherd P. Cohort profile: 1970 British birth cohort (BCS70). Int J Epidemiol 2006;35:836-43

77 Power C, Elliott J. Cohort profile: 1958 British birth cohort (National Child Development Study). Int J Epidemiol 2006;35:34-41

78 Marmot M, Brunner E. Cohort profile: the Whitehall II study. Int J Epidemiol 2005;34:251-6. 
79 Korkeila K, Suominen S, Ahvenainen J, Ojanlatva A, Rautava P, Helenius H, et al. Non-response and related factors in a nation-wide health survey. Eur J Epidemiol 2001;17:991-9.

80 Vahtera J, Poikolainen K, Kivimäki M, Ala-Mursula L, Pentti J. Alcohol intake and sickness absence: a curvilinear relation. Am J Epidemiol 2002;156:969-76.

81 Peter R, Alfredsson L, Hammar N, Siegrist J, Theorell T, Westerholm P. High effort, low reward, and cardiovascular risk factors in employed Swedish men and women: baseline results from the WOLF Study J Epidemiol Community Health 1998:52:540-7.

82 Alfredsson L, Hammar N, Fransson E, de Faire U, Hallqvist J, Knutsson A, et al. Job strain and major risk factors for coronary heart disease among employed males and females in a Swedish study on work, lipids and fibrinogen. Scand $J$ Work Environ Health 2002;28:238-48.

83 Summerfield M, Freidin S, Hahn M, Ittak P, Li N, Macalalad N, et al. HILDA use manual-release 12. Melbourne Institute of Applied Economic and Social Research, University of Melbourne, 2013

84 De Bacquer D, Pelfrene E, Clays E, Mak R, Moreau M, De Smet O, et al. Perceived job stress and incidence of coronary events: 3-year follow-up of the Belgian Job Stress Project cohort. Am J Epidemiol 2005;161:434-41.

85 Krause N, Brand RJ, Kauhanen J, Kaplan GA, Syme SL, Wong CC, et al. Work time and 11-year progression of carotid atherosclerosis in middle-aged Finnish men. Prev Chronic Dis 2009;6:A13.

86 Reis JP, Dubose KD, Ainsworth BE, Macera CA, Yore MM. Reliability and validity of the occupational physical activity questionnaire. Med Sci Sports Exerc 2005;37:2075-83.

87 Stockwell T, Donath S, Cooper-Stanbury M, Chikritzhs T, Catalano P, Mateo C. Under-reporting of alcohol consumption in household surveys: a comparison of quantity-frequency, graduated-frequency and recent recall. Addiction 2004;99:1024-33.

88 Balshem H, Helfand M, Schunemann HJ, Oxman AD, Kunz R, Brozek J, et al. GRADE guidelines: 3 . Rating the quality of evidence. J Clin Epidemiol 2011;64:401-6.

89 Holmes MV, Dale CE, Zuccolo L, Silverwood RJ, Guo Y, Ye Z, et al. Association between alcohol and cardiovascular disease: Mendelian randomisation analysis based on individual participant data. BMJ 2014;349:g4164.
90 Frone MR. Work stress and alcohol use. Alcohol Res Health 1999;23:284-91.

91 Karasek RA. Job demands, job decision latitude and mental strain: implications for job redesign. Admin Sci Quart 1979;24:285-307.

92 Kivimäki M, Nyberg ST, Batty GD, Fransson E, Heikkilä K, Alfredsson L, et al. Job strain as a risk factor for coronary heart disease: a collaborative meta-analysis of individual participant data. Lancet 2012;380:1491-7.

93 Virtanen M, Ferrie JE, Singh-Manoux A, Shipley MJ, Vahtera J, Marmot MG, et al. Overtime work and incident coronary heart disease: the Whitehall II prospective cohort study. Eur Heart J 2010;31:1737-44.

94 Friedman M, Rosenman RH. Type A behavior pattern: its association with coronary heart disease. Ann Clin Res 1971;3:300-12.

95 Midford R, Welander F, Allsop S. Preventing alcohol and other drug problems in the workplace. In: Stockwell T, Gruenewald PJ, Toumbourou JW, Loxley W, eds. Preventing harmful substance use. The evidence base for policy and practice. John Wiley, 2005.

96 Frone MR, Brown AL. Workplace substance-use norms as predictors of employee substance use and impairment: a survey of U.S. workers. J Stud Alcohol Drugs 2010;71:526-34

97 Mulder RT. Alcoholism and personality. Aust N Z J Psychiatry 2002;36:44-52.

98 Drago R, Wooden M, Black D. Long work hours: volunteers and conscripts. Br J Ind Relations 2009:47:571-600.

Accepted: 17 November 2014

\section{Cite this as: BMJ 2015;350:g7772}

This is an Open Access article distributed in accordance with the Creative Commons Attribution Non Commercial (CC BY-NC 4.0) license, which permits others to distribute, remix, adapt, build upon this work non-commercially, and license their derivative works on different terms, provided the original work is properly cited and the use is non-commercial. See: http://creativecommons.org/licenses/by-nc/4.0/. 


\section{Figures}

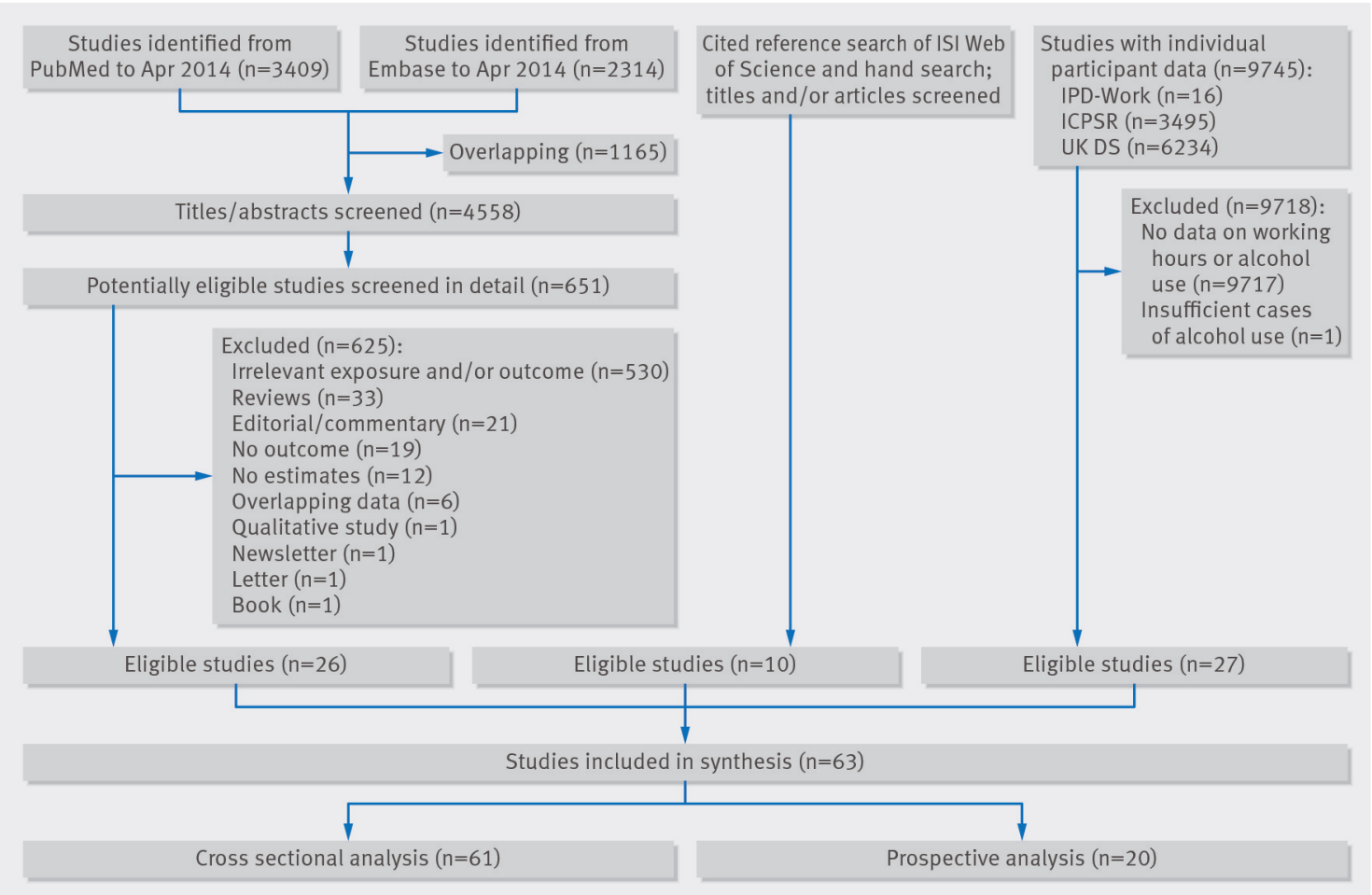

Fig 1 Search strategy and selection of studies for meta-analysis of effect of long working hours on alcohol use 


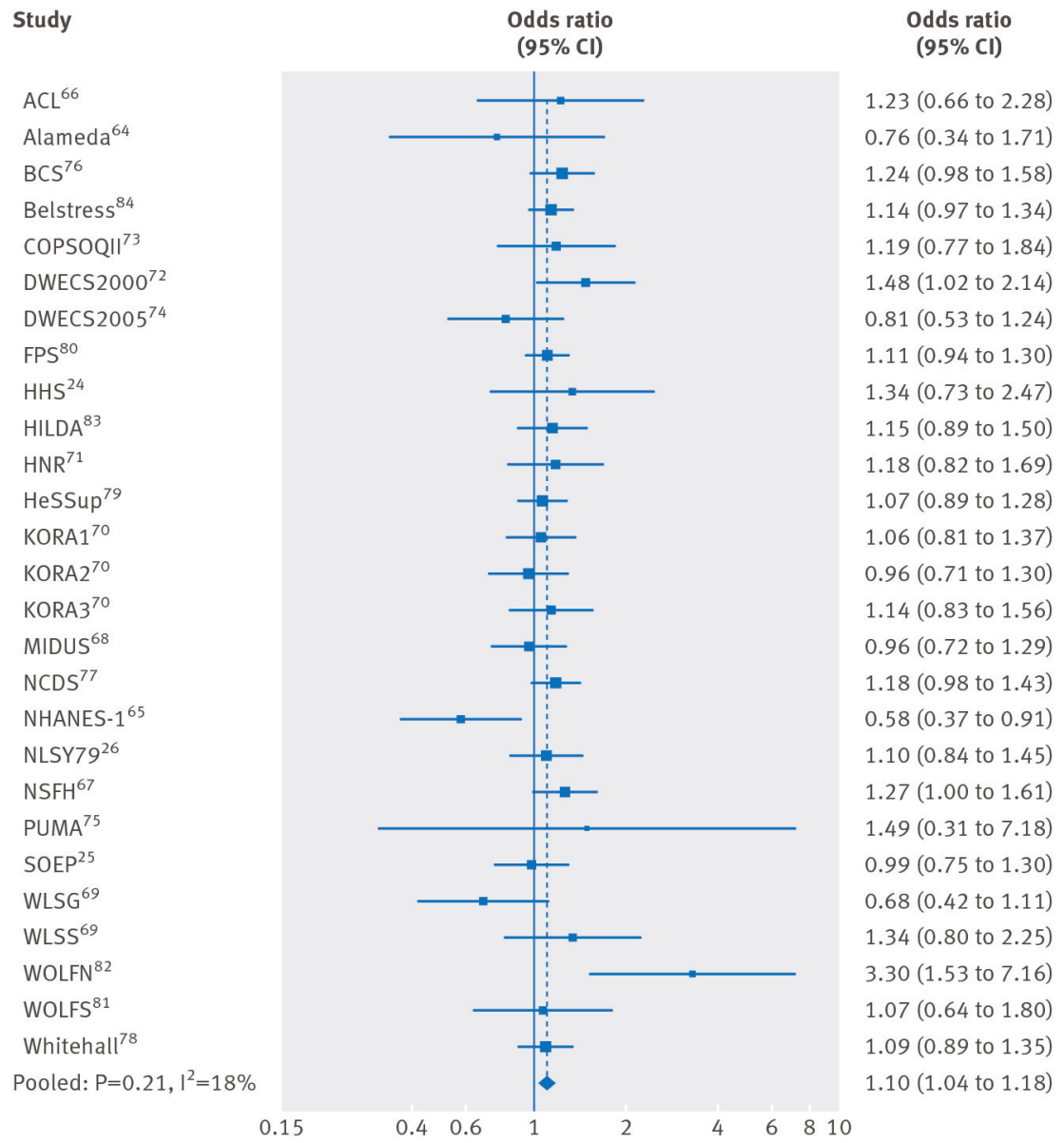

Fig 2 Cross sectional associations between long working hours and alcohol use from individual participant data adjusted for sex, age, socioeconomic status, and ethnicity 


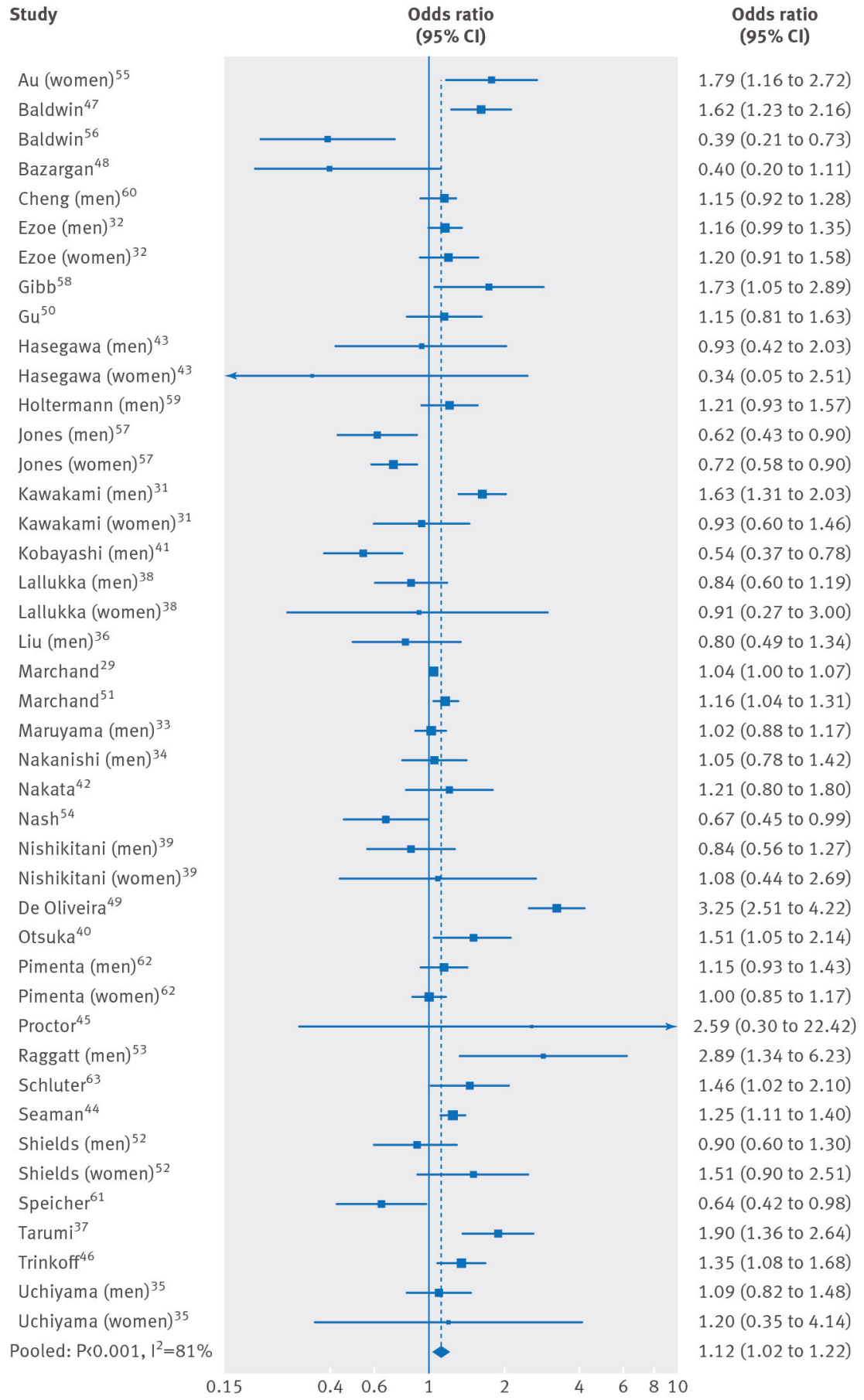

Fig 3 Cross sectional associations between long working hours and alcohol use from published data 


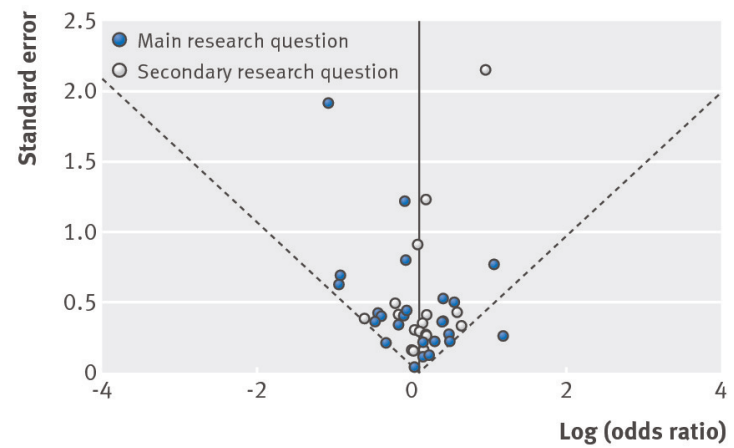

Fig 4 Funnel plot with pseudo 95\% confidence limits stratified by whether long working hours and alcohol use was main or secondary research question

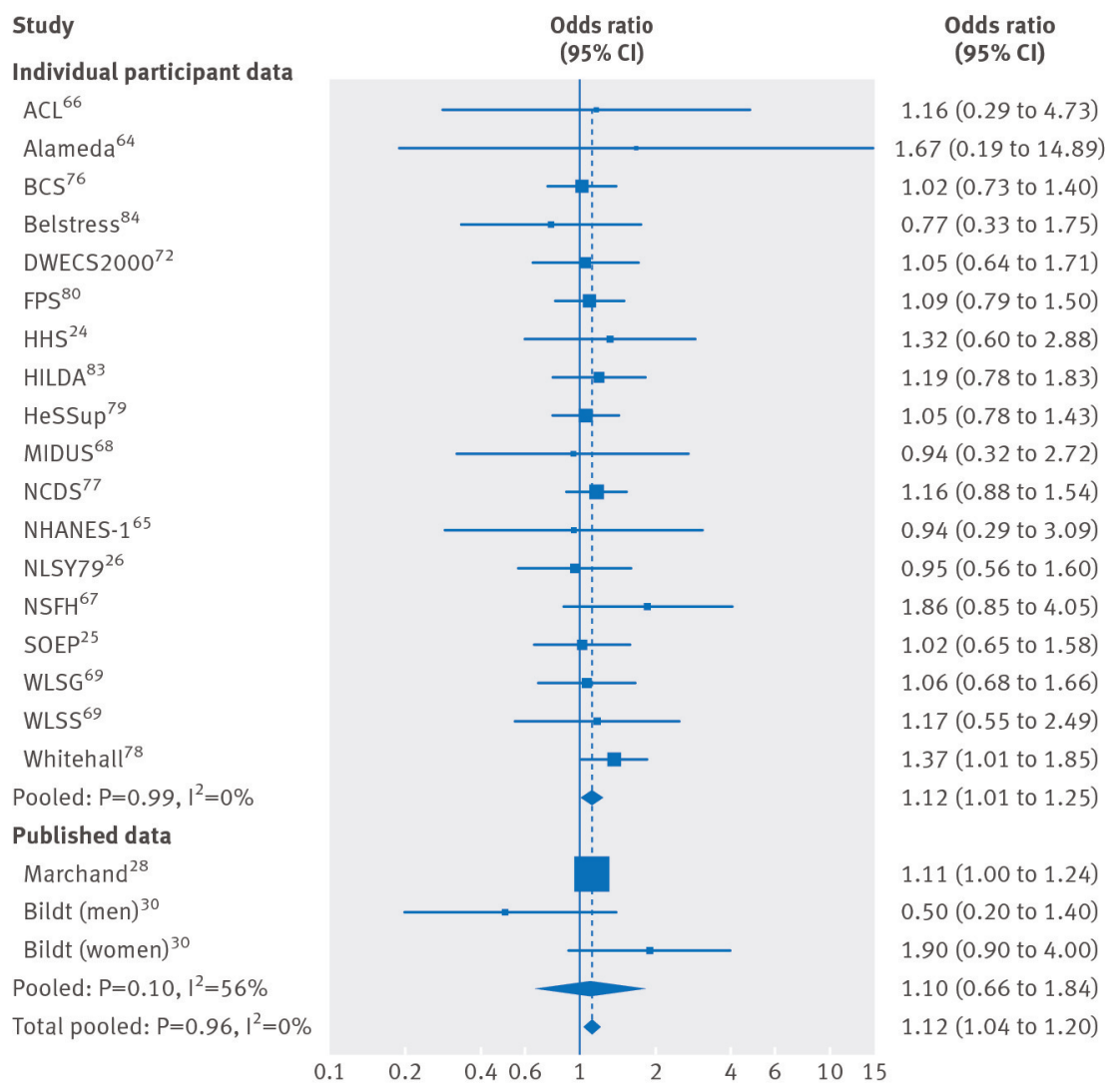

Fig 5 Associations between long working hours and new onset risky alcohol use (individual participant data adjusted for sex, age, socioeconomic status, and ethnicity at baseline) 


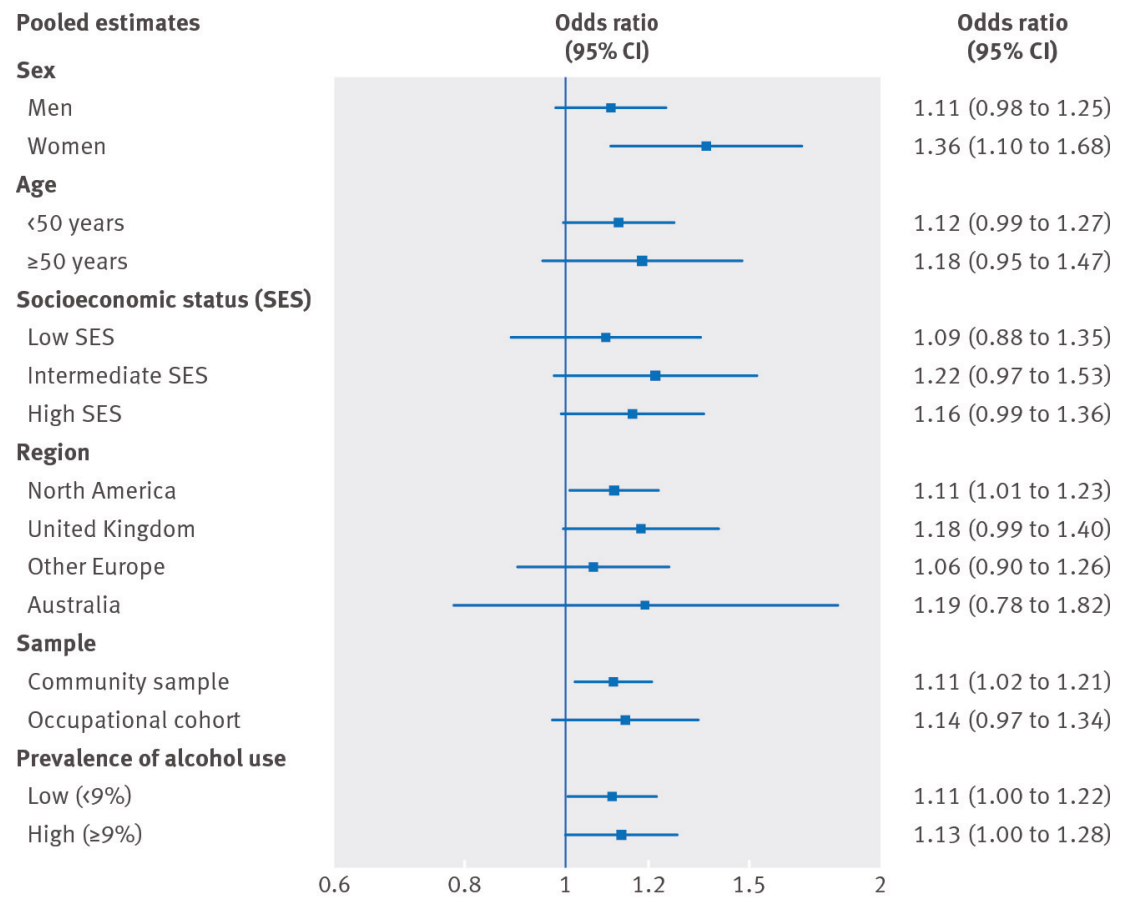

Fig 6 Pooled associations between long working hours and new onset risky alcohol use by sex, age group, socioeconomic status, geographic region, sample type, and prevalence of risky alcohol use in cohort

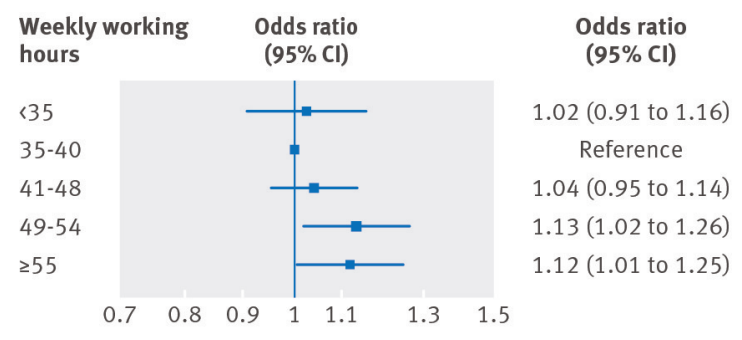

Fig 7 Pooled association between weekly working hours and new onset risky alcohol use, adjusted for sex, age, socioeconomic status, and ethnicity at baseline 